\title{
Comunicación

\section{Maestrías en Comunicación en México: análisis comparativo de sus perfiles de producción y reproducción académica}

\section{RAÚL FUENTES NAVARRO1}

Con base en datos bibliográficos provenientes de una investigación sobre la estructuración académica de los posgrados en comunicación, este artículo expone algunas constantes y diferencias encontradas en las tesis de maestría en Comunicación presentadas en cinco universidades mexicanas entre 1996 y 2005, para derivar de ellas algunas hipótesis sobre los perfiles de producción y reproducción del campo académico de la comunicación.

PALABRAS CLAVE: posgrados en Comunicación, México, campo académico, maestrías, bibliografía.
This paper displays some common and some specific trends found in a comparative analysis of bibliometric data shown by a set of master's degree theses, presented between 1996 and 2005 in five Mexican universities. This is done in order to derive from them some hypotheses about the profiles of production and reproduction in the academic field of communication.

KEY WORDS: Communication studies, México, academic field, master's degrees, bibliography.

1 Instituto Tecnológico y de Estudios Superiores de Occidente, México.

Correo electrónico: raul@iteso.mx 
Este artículo expone una continuación directa de los análisis descriptivos publicados previamente, tanto en Comunicación y Sociedad (Fuentes, 2007a, 2008), como en otras revistas académicas (2006, 2007b). Responde, como los textos anteriores, al objetivo de:

Analizar comparativamente la constitución de redes científicas y núcleos de especialización, mediante la identificación de convergencias temáticoreferenciales y teórico-metodológicas en las tesis de posgrado, en el contexto de la institucionalización, profesionalización y legitimación del campo académico de la comunicación en México y en Brasil (Fuentes, 2004, p. 1).

Lo anterior orientó un proyecto de investigación formalmente concluido en 2008, pero con fuertes necesidades de continuidad, en el esfuerzo por extender y profundizar el reconocimiento de las condiciones sociales, institucionales y discursivas que determinan la constitución científica de los estudios sobre la comunicación, un objeto genérico de estudio al que se le atribuyen relevancia y protagonismo crecientes en tanto estructuras y prácticas de ordenación del mundo social.

Al plantear como objeto de este análisis los "perfiles de producción y reproducción académica" que pueden detectarse a partir de las bibliografías de las tesis de maestría en Comunicación presentadas entre 1996 y 2005 en cinco universidades mexicanas, se intenta aportar evidencias empíricas a la interpretación de factores y tendencias que permitan evaluar, desde el interior mismo del campo académico, las condiciones de desarrollo de este sector, "más allá" de los indicadores bibliométricos, cuya información requiere de una adecuada contextualización, que a su vez puede ser mejor realizada desde un marco de análisis comparativo. De cualquier manera, a lo más que se pretende llegar es a la formulación de algunas hipótesis que puedan seguir siendo trabajadas sistemáticamente.

\section{EL CONTEXTO INSTITUCIONAL}

DE LOS PROGRAMAS DE MAESTRÍA EN COMUNICACIÓN

El grado académico de maestría, si bien claramente definido y establecido en el sistema mexicano de educación superior, es institucionalmente ambiguo, pues está situado como un grado "intermedio" del 
nivel del posgrado (entre la especialidad y el doctorado), y como tal carece de la precisa orientación profesionalizante de la licenciatura y la especialidad, al mismo tiempo que de la misión de formación de investigadores, como el doctorado. Es un grado que puede servir tanto para la actualización, la profundización o la extensión de la formación profesional, como para la profesionalización científica. De los aproximadamente 160,000 estudiantes de posgrado inscritos en el país en 2007, más de $110,000(68 \%)$ lo estaban en programas de maestría, y apenas $15,000(9 \%)$ en programas de doctorado, como indica la Tabla 1, donde queda también en evidencia la gran proporción de los programas y los estudiantes que corresponde al área de "ciencias sociales y administrativas", aunque la mayor parte de ellos son de "administración".

De los 3,742 programas de maestría registrados, apenas 595 (15.9\%) estaban incluidos en mayo de 2009 en el Padrón Nacional de Posgrados de Calidad (PNPC), ${ }^{2}$ entre ellos cinco dedicados al estudio de la comunicación. Este padrón, administrado de manera conjunta entre la Secretaría de Educación Pública (SEP) a través de la Subsecretaría de Educación Superior y el Consejo Nacional de Ciencia y Tecnología (CONACyT), establece como misión la de "fomentar la mejora continua y el aseguramiento de la calidad del posgrado nacional, que dé sustento al incremento de las capacidades científicas, tecnológicas, sociales, humanísticas, y de innovación del país". ${ }^{3}$ En el Marco de Referencia para la Evaluación y Seguimiento de Programas de Posgrado 4 se establece que el PNPC "está conformado por dos vertientes":

1. El Padrón Nacional de Posgrados (PNP), integrado por dos niveles de calidad:

- Competencia internacional.

- Consolidados.

2 Recuperado el 3 de octubre de 2009 de http://www.conacyt.gob.mx/Calidad/Listado_PNPC_2009.pdf

3 Recuperado el 3 de octubre de 2009 de http://www.conacyt.gob.mx/Calidad/Becas_ProgramasPosgradosNacionalesCalidad.html

4 Recuperado el 3 de octubre de 2009 de http://www.conacyt.gob.mx/Posgrados/Convocatorias/2009/Marco_Referencia_Posgrado_2009.pdf 


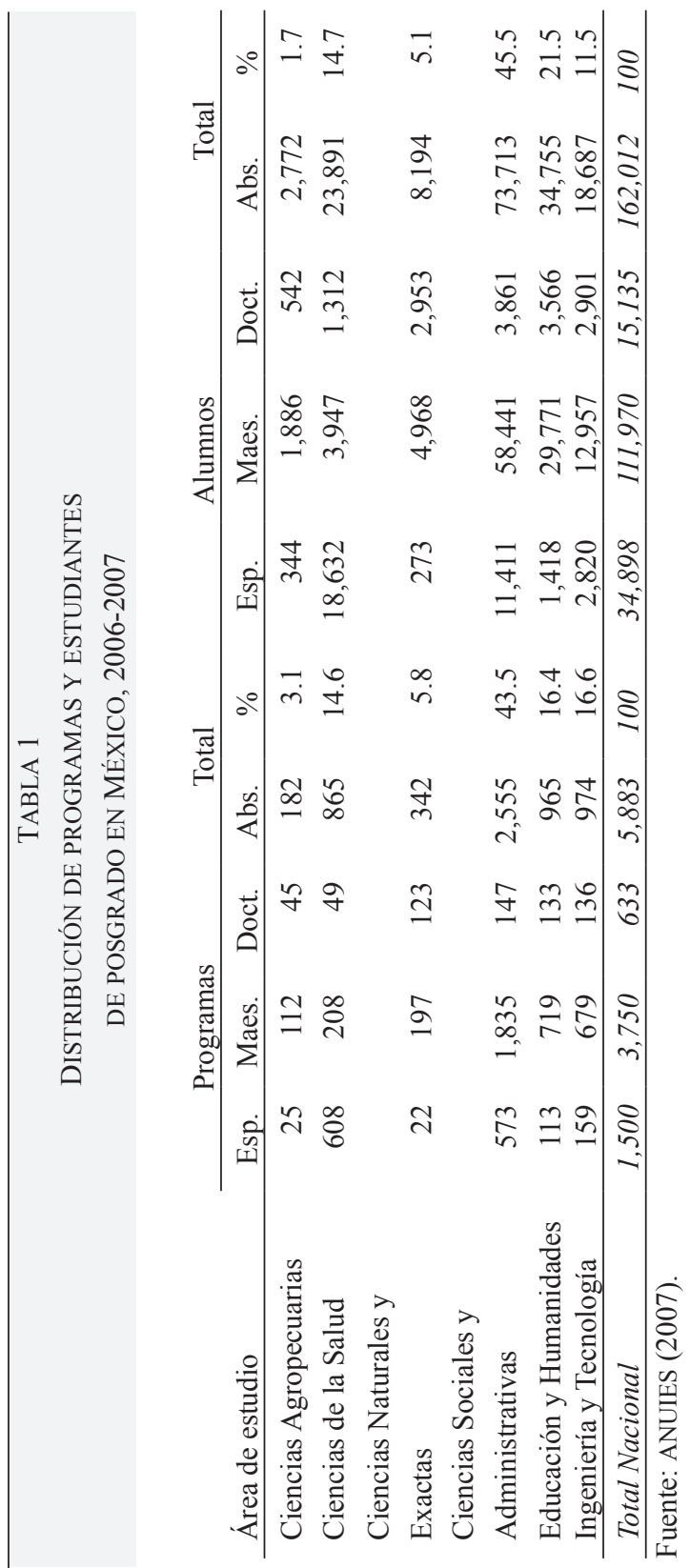


2. El Programa de Fomento a la Calidad del Posgrado (PFCP), integrado por dos niveles de calidad:

- En consolidación.

- Reciente creación.

Dicho Marco también establece que "los campos de orientación de los programas académicos de posgrado son dos: los Programas de Posgrado con Orientación Profesional, que ofrecen los niveles de especialidad o de maestría, y los Programas de Posgrado con Orientación a la Investigación, que ofrecen los niveles de maestría o de doctorado".

El sistema de evaluación se basa en seis "categorías": a) estructura del programa, b) estudiantes, c) personal académico, d) infraestructura y servicios, e) resultados, y f) cooperación con otros actores de la sociedad, y 19 "criterios" que las especifican. 5 Los parámetros de evaluación, según el nivel y la orientación de cada programa imponen mínimos, en muchos de los indicadores de los criterios, para otorgar y sostener un determinado "nivel de calidad", definido finalmente por un comité de pares y el Consejo Nacional de Posgrado. De esa acreditación depende la posibilidad del programa de recibir apoyos oficiales, especialmente becas para sus estudiantes.

Los cinco programas de maestría en Comunicación incorporados al PNPC, todos con calificación de "Consolidados", se distinguen

5 Los 19 criterios son: Plan de estudios (perfiles de ingreso y egreso, objetivos y metas, etc.); Proceso de enseñanza-aprendizaje (flexibilidad curricular, evaluación); Ingreso de estudiantes (proceso de selección); Trayectoria escolar (seguimiento de trayectoria, opciones de graduación); Movilidad e intercambio de estudiantes; Tutorías; Becas; Núcleo académico básico (perfil, organización, evaluación); Líneas de generación y/o aplicación del conocimiento; Espacios y equipamiento; Laboratorios y talleres; Información y documentación (Biblioteca); Tecnologías de información y comunicación (equipos, redes, servicios); Trascendencia, cobertura y evolución del programa; Seguimiento de egresados; Efectividad del posgrado (eficiencia terminal y graduación); Contribución al conocimiento; Vinculación y Financiamiento. 
así del resto de los más de 40 que operan en el país. ${ }^{6}$ La maestría en Comunicación de la Universidad Nacional Autónoma de México (UNAM), la de la Universidad de Guadalajara (UdeG) y la del ITESO (maestría en Comunicación de la Ciencia y la Cultura) están consideradas en el PNP como "programas de posgrado con orientación a la investigación", mientras que las de la Universidad Iberoamericana (UIA) y el Tecnológico de Monterrey (ITESM), como "programas de posgrado con orientación profesional". Su antigüedad y número de estudiantes es diverso, así como lo son las estructuras académicas que las sustentan, aunque comparten los mismos parámetros (y resultados) de evaluación y muchos de los rasgos de inserción dentro del campo académico de la comunicación.

Según la producción académica recopilada en el sitio ccdoc (Documentación en Ciencias de la Comunicación), ${ }^{7}$ estas cinco instituciones, junto con la UniversidadAutónoma Metropolitana(UAM), ${ }^{8}$ dan cuenta en conjunto de tres cuartas partes de las publicaciones de investigación en el país en las últimas dos décadas (véase Tabla 2). También, en esas seis instituciones se concentra la adscripción de 56\% de los investigadores de la comunicación reconocidos por el Sistema Nacional de Investigadores (SNI) (véase Tabla 3). Datos como estos, y la inexistencia de programas de doctorado "en comunicación", permiten caracterizar el estado de las estructuras de investigación y posgrado en comunicación en el país como un "estancamiento concentrado" (Fuentes, 2009).

6 Adicionalmente, la "eficiencia terminal", uno de los factores determinantes de la acreditación, excluye necesariamente de un análisis de las tesis a los programas no acreditados, donde el número de titulados (aunque no en todos los casos el de estudiantes) es extremadamente bajo.

7 El sitio "ccdoc" (http://ccdoc.iteso.mx), disponible en Internet desde 2003, reúne las referencias (y aproximadamente $40 \%$ de ellas con acceso a los textos completos) de los productos publicados de la investigación de la Comunicación en México (libros, capítulos, artículos, tesis de posgrado), como derivación de las sistematizaciones documentales publicadas en forma de libros por Raúl Fuentes Navarro en 1988, 1996 y 2003.

8 Que en su Unidad Xochimilco ofrece también una maestría en Comunicación y Política, actualmente no acreditada en el PNP. 


\section{TABLA 2}

PRODUCTOS PUBLICADOS DE INVESTIGACIÓN DE LA COMUNICACIÓN, POR INSTITUCIÓN DE ADSCRIPCIÓN DE SUS AUTORES, 1995-2008

\begin{tabular}{lrrr}
\multicolumn{1}{c}{$\begin{array}{c}\text { Institución de } \\
\text { adscripción }\end{array}$} & $1995-2001$ & $2002-2008$ & $1995-2008$ \\
\hline UdeG (CUCSH) & $204(14.9 \%)$ & $149(15.1 \%)$ & $353(15.0 \%)$ \\
UNAM (todas las & $144(10.5 \%)$ & $182(18.6 \%)$ & $326(13.8 \%)$ \\
dependencias) & & & \\
ITESO (DESO) & $144(10.5 \%)$ & $120(12.2 \%)$ & $264(11.2 \%)$ \\
UIA (todos los planteles) & $176(12.9 \%)$ & $88(8.9 \%)$ & $264(11.2 \%)$ \\
UAM (todas las unidades) & $132(9.7 \%)$ & $107(10.8 \%)$ & $239(10.2 \%)$ \\
ITESM (todos los & $72(5.3 \%)$ & $38(3.8 \%)$ & $110(4.7 \%)$ \\
campus) & & & \\
Otras instituciones & $493(36.2 \%)$ & $302(30.6 \%)$ & $795(33.9 \%)$ \\
Totales & $1,365(100 \%)$ & $986(100 \%)$ & $2,351(100 \%)$ \\
\hline
\end{tabular}

Fuente: $c c d o c$, al 15 de octubre de 2008.

Para el proyecto del que se deriva el presente análisis se conformó un corpus con las tesis de maestría en comunicación presentadas entre 1996 y 2005 en los cinco programas acreditados, de las cuales pudieron recuperarse (con la colaboración de los respectivos coordinadores y bibliotecas institucionales) 356, aproximadamente $85 \%$ del total de la producción en ese periodo. ${ }^{9}$ En la Tabla 4 se muestra la distribución por

9 Es interesante constatar las dificultades encontradas para conseguir los ejemplares de las tesis, fuera en papel o en archivos digitales, a pesar de la excelente disposición de los coordinadores de los programas, y de que en todas las instituciones hay proyectos vigentes para disponibilizar las tesis en sitios digitales. A partir de los ejemplares conseguidos se pudieron conformar dos bases de datos: una con las tesis como unidades, y otra con las bibliografías contenidas en ellas. El tiempo y esfuerzo necesarios para conseguir los materiales y para sistematizar la información quizás expliquen en parte la escasez de estudios de este tipo en el país, por lo que destacan recursos de acceso abierto vía Internet, como ccdoc para la investigación académica de la comunicación en México, o Redalyc (Red 


\section{TABLA 3}

MIEMBROS DEL SNI, 2008, POR INSTITUCIÓN DE ADSCRIPCIÓN Y NIVEL, QUE HACEN INVESTIGACIÓN DE LA COMUNICACIÓN

\begin{tabular}{|c|c|c|c|c|c|c|}
\hline $\begin{array}{l}\text { Institución de } \\
\text { adscripción }\end{array}$ & $\begin{array}{l}\text { Investi- } \\
\text { gadores }\end{array}$ & $\begin{array}{l}\text { Can- } \\
\text { didato }\end{array}$ & $\begin{array}{c}\text { Nivel } \\
\text { I }\end{array}$ & $\begin{array}{c}\text { Nivel } \\
\text { II }\end{array}$ & $\begin{array}{c}\text { Nivel } \\
\text { III }\end{array}$ & $\begin{array}{l}\text { Emé- } \\
\text { rito }\end{array}$ \\
\hline $\begin{array}{l}\text { UNAM (todas las } \\
\text { dependencias) }\end{array}$ & 29 & 1 & 17 & 8 & 3 & 0 \\
\hline $\begin{array}{l}\text { UAM (todas las } \\
\text { unidades) }\end{array}$ & 18 & 1 & 7 & 9 & 0 & 1 \\
\hline UdeG (CUCSH) & 17 & 0 & 11 & 4 & 2 & 0 \\
\hline $\begin{array}{l}\text { ITESM (todos los } \\
\text { campus) }\end{array}$ & 11 & 2 & 6 & 2 & 1 & 0 \\
\hline $\begin{array}{l}\text { UIA (todos los } \\
\text { planteles) }\end{array}$ & 4 & 0 & 2 & 2 & 0 & 0 \\
\hline ITESO (DESO) & 3 & 0 & 1 & 0 & 2 & 0 \\
\hline $\begin{array}{l}\text { Otras } 28 \\
\text { instituciones } \\
\text { públicas }\end{array}$ & 53 & 7 & 41 & 5 & 0 & 0 \\
\hline $\begin{array}{l}\text { Otras } 3 \text { universi- } \\
\text { dades privadas }\end{array}$ & 5 & 1 & 3 & 1 & 0 & 0 \\
\hline No especificada & 5 & 1 & 2 & 2 & 0 & 0 \\
\hline Total & 145 & 13 & 90 & 33 & 8 & 1 \\
\hline
\end{tabular}

Fuente: elaboración propia con datos del SNI.

institución y por año de este corpus. Algunas diferencias notables quedan en evidencia en la Tabla 4, como la desproporción entre instituciones en cuanto al número de tesis, explicable en principio por el tamaño mismo de las universidades y los programas, pero también porque las maestrías del ITESO y la UdeG comenzaron a operar apenas en 1998.10

de Revistas Científicas de América Latina y el Caribe, España y Portugal) (http://redalyc.uaemex.mx), para las revistas científicas de la región.

10 Aunque en ambos casos se agregaron al corpus algunas tesis provenientes, en el caso del ITESO, de la versión anterior del programa: la maestría en 


\section{TABLA 4}

TESIS DE MAESTRÍA EN COMUNICACIÓN PRESENTADAS EN MÉXICO ENTRE 1996 Y 2005, POR AÑO E INSTITUCIÓN

\begin{tabular}{|c|c|c|c|c|c|c|c|c|c|c|c|}
\hline & ஃ & $\hat{\sigma}$ & $\stackrel{\infty}{\stackrel{2}{\Omega}}$ & ڤे & 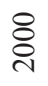 & $\underset{\sim}{\overline{8}}$ & 교 & @ి & 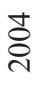 & ஜ & \\
\hline UNAM & 6 & 6 & 11 & 8 & 9 & 10 & 11 & 10 & 21 & 20 & 112 \\
\hline UdeG & 0 & 0 & 3 & 0 & 1 & 3 & 7 & 10 & 14 & 3 & 41 \\
\hline ITESO & 0 & 1 & 0 & 2 & 0 & 0 & 2 & 7 & 10 & 8 & 30 \\
\hline UIA & 4 & 6 & 11 & 9 & 11 & 6 & 4 & 12 & 11 & 10 & 84 \\
\hline ITESM & 5 & 8 & 8 & 10 & 13 & 12 & 7 & 6 & 12 & 8 & 89 \\
\hline Totales & 15 & 21 & 33 & 29 & 34 & 31 & 31 & 45 & 68 & 49 & 356 \\
\hline
\end{tabular}

Aunque quizás el dato más interesante sea que casi dos tercios de las tesis $(63 \%)$ hayan sido presentadas en el lustro más reciente del periodo, lo cual indica un crecimiento de la producción que apenas comienza a consolidarse. ${ }^{11}$

\section{PERFILES FORMALES Y TEMÁTICOS \\ DE LAS TESIS DE MAESTRÍA EN COMUNICACIÓN}

En el conjunto, las tesis de maestría en Comunicación analizadas son documentos formales, cuya extensión promedia 172.6 páginas y contienen una media de 74.3 referencias en sus bibliografías. Hay, sin embar-

Comunicación que operó entre 1985 y 1993, y en el caso de la UdeG, de la especialidad en Comunicación Social de la maestría en Ciencias Sociales. En los dos casos, se trata de productos generados por estudiantes dirigidos por el personal académico que a partir de 1998 formó la base de los programas actuales (Fuentes, 2007a).

11 Si bien es bastante reducido y "estable" (o "estancado"), en comparación con lo sucedido en Brasil en el mismo periodo, donde se localizaron 2,663 tesis de mestrado em comunicação (además de 1,070 tesis de doctorado), provenientes de 10 instituciones. En 2009 el número de programas de posgrado en comunicación acreditados en Brasil llegó a 35, cuando en 1996 eran 11 y en 2005, 21 (Romancini, 2006, p.100). 
go, algunas diferencias significativas por institución (véase Tabla 5), y por temática, que se describen más adelante.

\section{TABLA 5}

TESIS DE MAESTRÍA EN COMUNICACIÓN PRESENTADAS EN

MÉXICO ENTRE 1996 Y 2005, POR UNIVERSIDAD, NÚMERO PROMEDIO

DE PÁGINAS Y DE REFERENCIAS

\begin{tabular}{lccc}
\multicolumn{2}{l}{ Tesis de maestría en Comunicación } & $\begin{array}{c}\text { Páginas } \\
\text { (media/tesis) }\end{array}$ & $\begin{array}{c}\text { Referencias } \\
\text { (media/tesis) }\end{array}$ \\
\hline UNAM & 112 & 199.8 & 93.4 \\
UdeG & 41 & 198.1 & 81.9 \\
ITESO & 30 & 171.1 & 82.1 \\
UIA & 84 & 206.9 & 78.7 \\
ITESM & 89 & 102.5 & 40.2 \\
Totales & 356 & 172.6 & 74.3 \\
\hline
\end{tabular}

Llama la atención de inmediato la particularidad de las tesis del ITESM, por el promedio notablemente más bajo en el número de páginas y el número de referencias que el de las otras instituciones, debido probablemente a que los estudios siguen un estilo de investigación más empirista y "situado" que las de las demás universidades, aunque esta característica también puede corresponder a otros factores, como las líneas temáticas y teórico-metodológicas, sobre los que se presentan algunos datos más adelante.

Bajo el supuesto de que hay amplia diversidad en los protocolos de investigación que dan lugar a las tesis de maestría en todas las universidades, se buscó explorar en este análisis la composición de las referencias anotadas en la "bibliografía" final de cada una de ellas, y se detectaron algunas diferencias al construir el perfil de citación de cada institución, que se expone en la Tabla 6:12

12 Los datos presentados en las Tablas 5 y 6 habían sido ya presentados en Fuentes (2008), pero aquí dan pie a otras relaciones. 


\begin{tabular}{|c|c|c|c|c|c|c|c|c|c|}
\hline \multicolumn{9}{|c|}{$\begin{array}{l}\text { PERFILES DE CITACIÓN EN TESIS DE MAESTRÍA EN } \\
\text { COMUNICACIÓN EN MÉXICO (1996-2005), POR INSTITUCI } \\
\text { TIPO DE FUENTES CITADAS (PROMEDIOS) }\end{array}$} & \\
\hline & 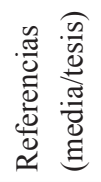 & 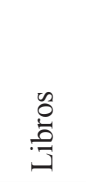 & 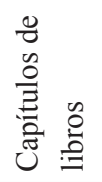 & 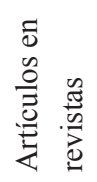 & $\frac{n}{\sqrt[s]{0}}$ & 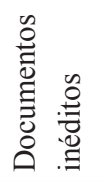 & 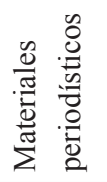 & 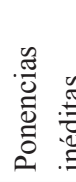 & \\
\hline UNAM & 93.4 & 52.6 & 5.2 & 5.2 & 2.1 & 8.9 & 18.5 & 0.5 & 9 \\
\hline UdeG & 81.9 & 43.4 & 13.2 & 14.1 & 1.4 & 6.8 & 2.3 & 0.7 & 7 \\
\hline ITESO & 82.1 & 39.9 & 11.6 & 10.8 & 1.2 & 14.1 & 2.7 & 1.8 & 8 \\
\hline UIA & 78.7 & 34.9 & 6.6 & 8.1 & 1.5 & 14.9 & 11.6 & 1.1 & 1 \\
\hline ITESM & 40.2 & 13.7 & 6.8 & 9.6 & 1.1 & 6.2 & 2.4 & 0.4 & 4 \\
\hline Totales & 74.3 & 36.6 & 7.4 & 8.5 & 1.5 & 9.8 & 9.6 & 0.5 & 9 \\
\hline
\end{tabular}

Como es típico de las ciencias sociales y las humanidades, en las tesis mexicanas de maestría en Comunicación la proporción mayor de las referencias proviene de libros: de las 26,472 referencias totales en el corpus, 13,029 corresponden a libros y 2,635 a textos incluidos como capítulos en libros, es decir, casi $60 \%$ del total en conjunto. Las tesis de la UNAM (61\%), el ITESO (63\%) y la UdeG (69\%), las tres maestrías catalogadas como "de investigación" en el PNP, superan ese promedio, mientras que las tesis de las dos maestrías "profesionalizantes", la UIA (53\%) y el ITESM (51\%), no lo alcanzan, aunque en todos los casos al menos la mitad de las referencias son estrictamente bibliográficas.

En contraparte, la "cientificidad" emergente de la investigación en comunicación, según los criterios y usos de las ciencias naturales, está representada en el corpus analizado por $11.4 \%$ global de referencias a artículos publicados en revistas académicas. Por institución, esta proporción es muy variable, pues asciende hasta $23.8 \%$ en las tesis del ITESM y $17.2 \%$ en las de la UdeG; con $13.2 \%$ en las del ITESO; $10.2 \%$ en las de la UIA, y sólo 5.6\% en las de la UNAM.13 Nuevamente, este dato

13 Se encontraron en las tesis referencias a artículos publicados en más de 1,000 revistas académicas, de las cuales sólo 166 fueron citadas cuatro 
remite a la consideración de los "estilos" institucionales de investigación y a los campos temáticos abordados, pues en todas estas universidades hay recursos bibliotecarios más que adecuados.

Para los efectos del proyecto del que se informa, sin embargo, cabe destacar dos índices representativos del padrón de citación encontrado en las tesis, y sus diferencias comparativas entre instituciones: el constituido por la suma de las referencias a libros, capítulos, artículos y tesis, es decir, al material publicado que puede considerarse como capital del campo académico, ${ }^{14} \mathrm{y}$ la proporción de estas referencias que aparecen al menos en $1 \%$ del conjunto de las tesis, es decir, en cuatro o más de ellas. Como se puede ver en la Tabla 7, de las 19,220 referencias totales a libros, capítulos, artículos y tesis (72.6\% del total), sólo 6,074 (31.6\% del recorte y $22.9 \%$ del total) cumplen la segunda condición.

Los datos de la Tabla 7 también indican que en todas las instituciones excepto la UIA, la media de referencias a fuentes publicadas en sus tesis (porcentaje del total de referencias seleccionadas) supera los dos tercios del total, pero el porcentaje de las referencias que apuntan hacia el capital bibliográfico del campo mínimamente compartido (citaciones analizables) en ningún caso llega a un tercio del total. Es decir, el recurso efectivo al capital bibliográfico del campo está extremadamente fragmentado. ${ }^{15}$ Conviene detallar un poco más esta condi-

o más veces (72 editadas en México, 32 en Iberoamérica y 62 en otros países "extranjeros"). Los títulos más frecuentemente citados fueron: Comunicación y Sociedad (256), Revista Mexicana de Comunicación (159) y Estudios sobre las Culturas Contemporáneas (81) entre los mexicanos; Diá-logos de la Comunicación (117), Chasqui (72) y Telos (45), entre los iberoamericanos; Journal of Communication (96), Media, Culture \& Society (39) y Communication Research (38) entre los "extranjeros".

14 Excluyendo las referencias a documentos inéditos, materiales periodísticos y ponencias no publicadas, fuentes primarias igualmente que los libros, revistas y tesis para las investigaciones, pero determinadas en alto grado por el objeto concreto de cada tesis, al cual en su mayoría documentan particularmente. Estas referencias excluidas del análisis dan cuenta de $27.4 \%$ de las referencias totales.

15 Si bien, como ya se expuso en Fuentes (2008, p.48), hay nueve textos que 


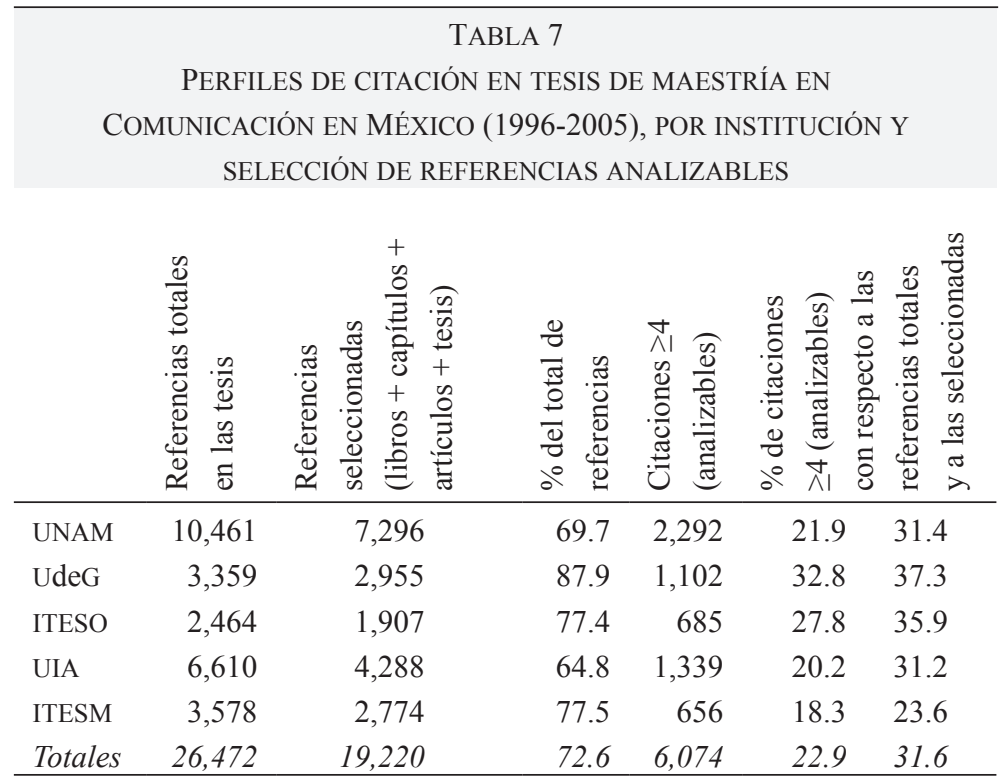

ción, en relación con las instituciones, pero también con los recortes temáticos de las tesis.

En cuanto al capital bibliográfico del campo académico y la distribución por institución de sus referencias, es interesante comparar las proporciones de las "citaciones analizables", es decir, las referencias que aparecen en cuatro o más de las tesis del corpus, según el origen de los autores (independientemente de si las ediciones citadas son traducciones al español). Para ello, se han formado cuatro categorías: autores

forman la "plataforma central" de la bibliografía fundamental para los "altos estudios" de comunicación en México: Ideología y cultura moderna de John B. Thompson; De los medios a las mediaciones de Jesús MartínBarbero; La era de la información de Manuel Castells; La construcción social de la realidad de Berger y Luckmann; Los media y la modernidad de John B. Thompson; La constitución de la sociedad de Anthony Giddens; Sociología y cultura de Pierre Bourdieu; La investigación de la comunicación de masas de Mauro Wolf; e Introducción a los métodos cualitativos de investigación de Taylor y Bogdan. 
angloparlantes; "extranjeros" de otras lenguas (ni inglés ni español); iberoamericanos y mexicanos. La distribución se presenta en la Tabla 8.

Con ligeras desviaciones y algunos sesgos interesantes, la distribución de las citaciones "analizables" en las tesis mexicanas de maestría en Comunicación, según el origen de los autores de las obras referidas, es sorprendentemente homogénea, pues indica que el capital bibliográfico del campo académico tiende a estar formado por cuatro "sectores" aproximadamente equivalentes (Fuentes, 2008, pp. 50-51). No se puede afirmar, por ello, que la investigación mexicana aquí representada esté basada en modelos "extranjeros" ni tampoco que lo esté primordialmente en aportes "propios". Con sus diferencias entre instituciones, este rasgo del perfil de citación no permite sustentar caracterizaciones sobre la "dependencia" o la "autonomía" nacionales en el campo. En términos generales, el capital bibliográfico así indicado remite por igual, casi por mitades, a la producción "extranjera"16 (donde sorprendentemente no predomina la producción "anglo"), ${ }^{17}$ y a la producción "iberoamericana", 18 la que está "pensada" originalmente en portugués, catalán y sobre todo español (donde sí predomina la nacional). ${ }^{19}$ Pero

16 Los autores “extranjeros" (no anglo) con mayor número de citaciones son: Pierre Bourdieu (222), Armand Mattelart (108), Umberto Eco (102) y Jürgen Habermas (97). La obra individual más citada es: La construcción social de la realidad (1968), de Peter Berger y Thomas Luckmann (46).

17 Los autores "angloparlantes" con mayor número de citaciones son: Anthony Giddens (115), John B. Thompson (110), Marshall McLuhan (57) y David Morley (53). La obra individual más citada es: Ideología y cultura moderna. Teoría crítica social en la era de la comunicación de masas (1993) de John B. Thompson (67).

18 Los autores "iberoamericanos" con mayor número de citaciones son: Jesús Martín-Barbero (185), Manuel Castells (72), Román Gubern (54) y Manuel Martín Serrano (44). La obra individual más citada es: De los medios a las mediaciones: comunicación, cultura y hegemonía (1987), de Jesús Martín-Barbero (53).

19 Los autores mexicanos con mayor número de citaciones son: Guillermo Orozco Gómez (284), Raúl Fuentes Navarro (159), Enrique E. Sánchez Ruiz (151) y Néstor García-Canclini (145). La obra individual más citada 


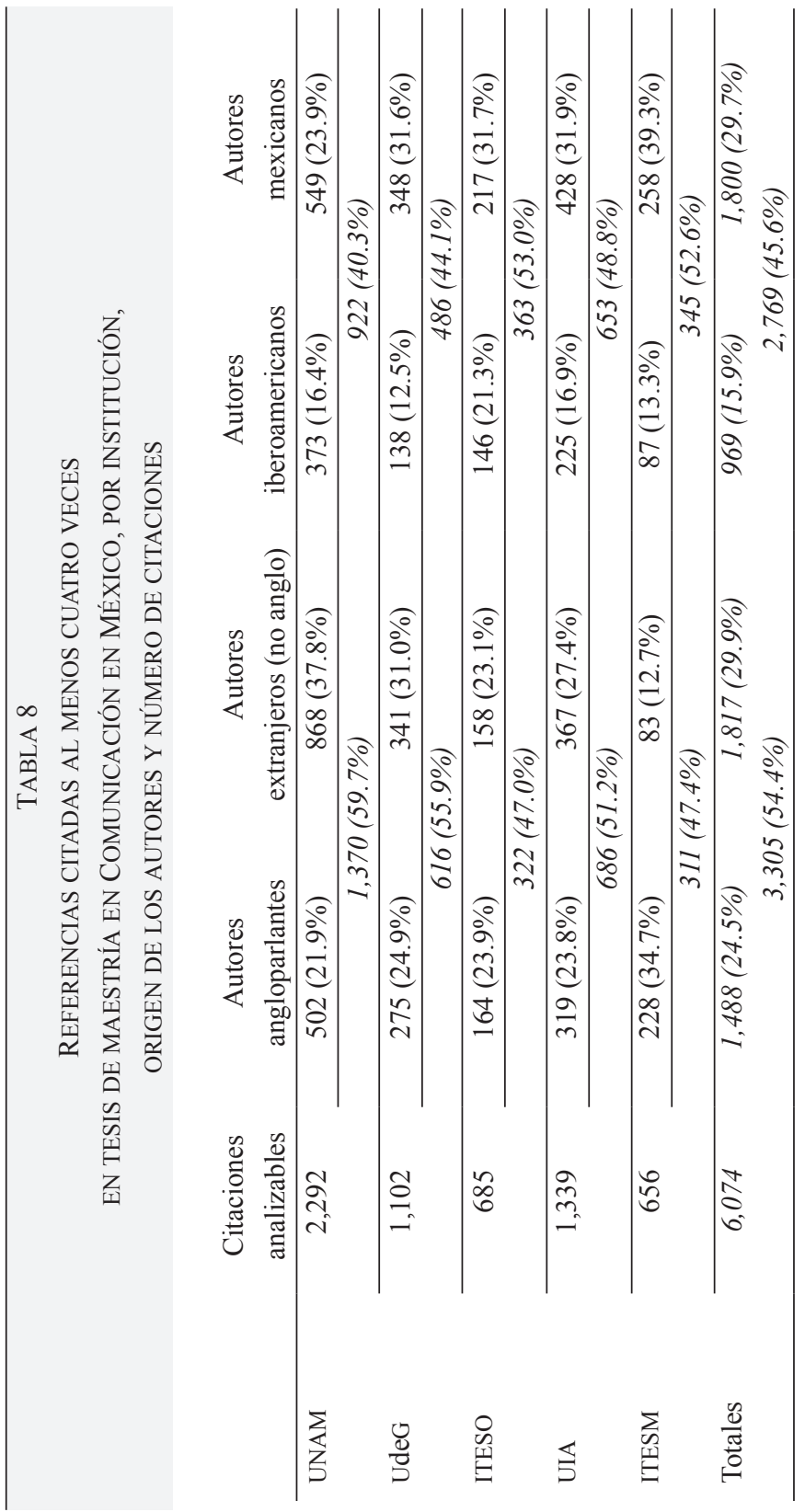


quizás ese aparentemente óptimo balance sea una manifestación más de la "fragmentación" que caracteriza a los estudios de comunicación en todo el mundo (Craig, 1999; Herkman, 2008).

La categorización temática, indispensable como "puerta de entrada" para analizar esa fragmentación es, sin embargo, hasta ahora un problema casi infranqueable. Los sistemas de categorías que necesariamente remiten a las "estructuras" disciplinarias, teóricas o epistemológicas del campo académico de la Comunicación, son una de las manifestaciones más vehementes, por su insuficiencia, de la inconsistencia que universalmente caracteriza al campo (Craig, 2008). Para el proyecto presente se adoptó (y adaptó) "provisionalmente" un sistema de categorías descriptivas derivado de una clasificación temática en proceso de desarrollo colegiado en Brasil, considerando sobre todo los propósitos comparativos asumidos. En su tesis doctoral sobre la institucionalización y el capital científico del campo académico de la comunicación en Brasil, Richard Romancini (2006, p.157) aplicó una división del campo de la comunicación en seis "subáreas" temáticas: Teoría de la comunicación; Periodismo y producción editorial (Editoração); Comunicación audiovisual: cine, radio y televisión; Comunicación organizacional, Relaciones públicas y propaganda; Cibercultura y tecnologías de la comunicación; Mediaciones e interfaces comunicacionales. La adaptación generada para la clasificación temática de las tesis de maestría mexicanas consistió en una "ramificación"20 subsecuente de estas seis "subáreas", la cual se expone en la Tabla 9, con las tesis de cada institución clasificadas en cada categoría y "subcategoría".

En los datos de la Tabla 9 hay claras evidencias de la fragmentación de la investigación de la comunicación en cuanto a las temáticas de las tesis de maestría, de alguna manera relacionadas directamente con las líneas

es: Teoría e investigación de la comunicación de masas (1996), de José Carlos Lozano Rendón (39).

20 La propuesta original se ubica en un proyecto, auspiciado por el Consejo Nacional de Investigación (CNPq) de Brasil, para la "reformulación de los árboles del conocimiento" empleados por esa agencia para la clasificación de los proyectos de investigación, por lo que la "ramificación" es una operación totalmente consistente (Romancini, 2006, p.158). 


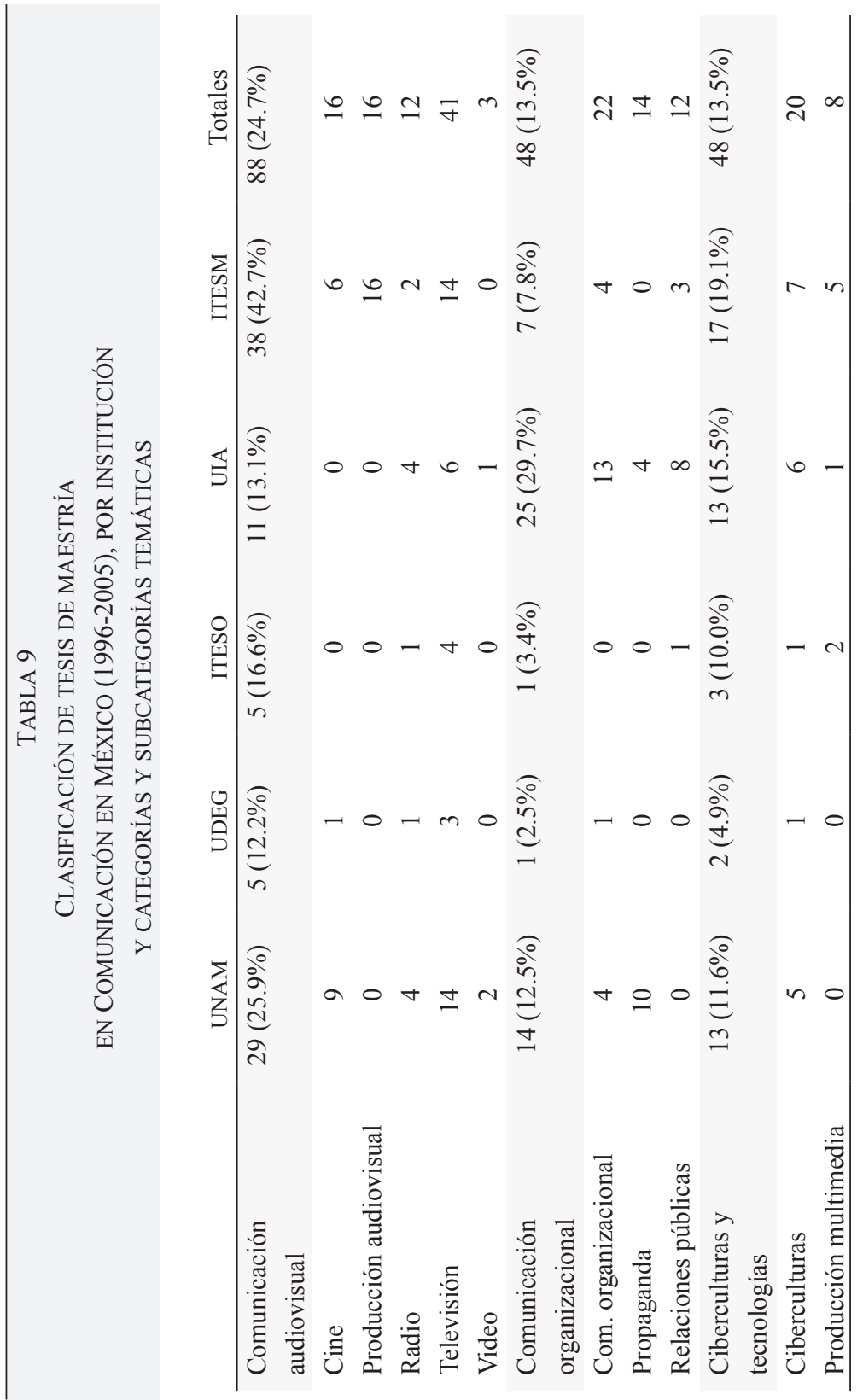




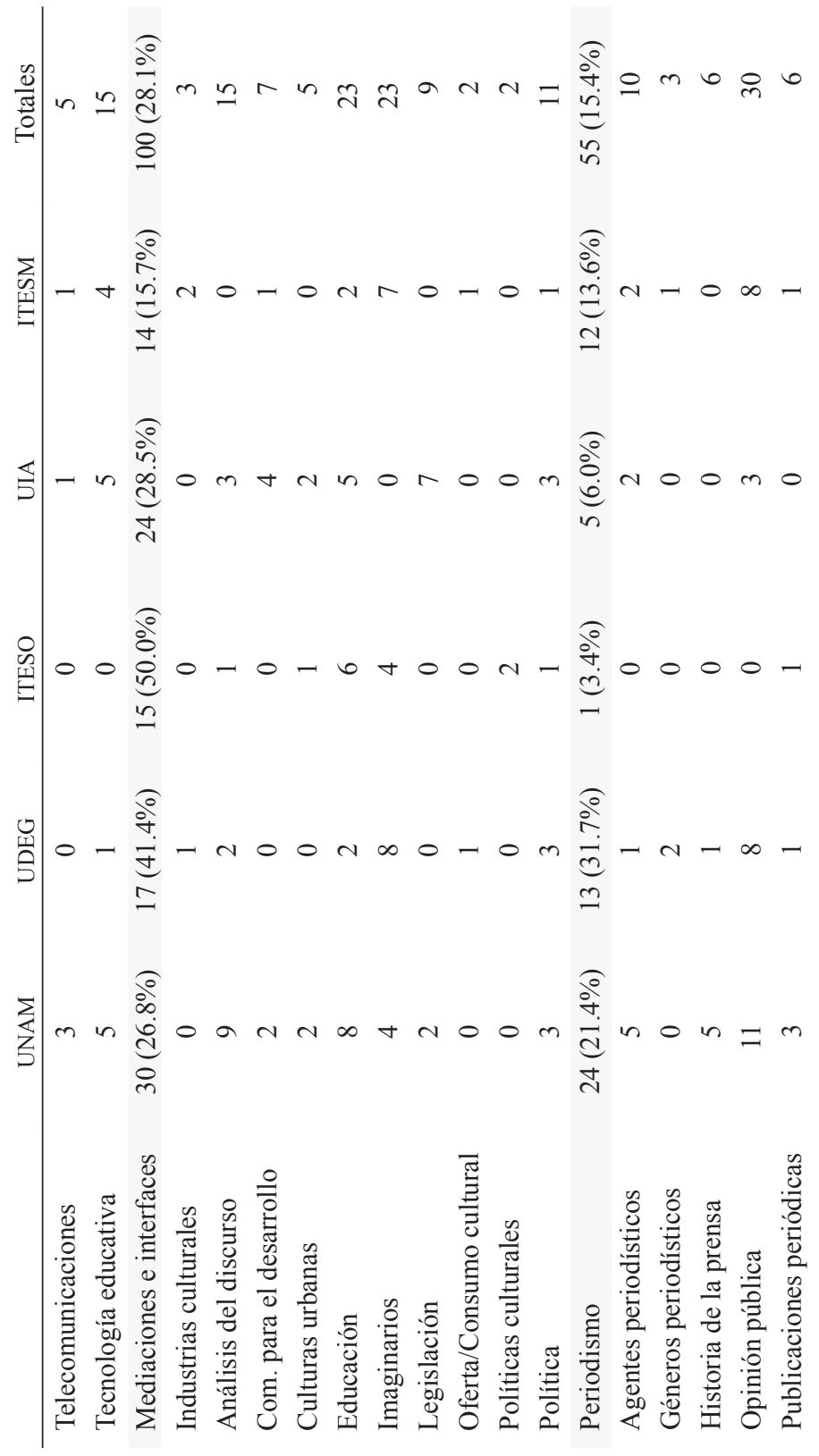




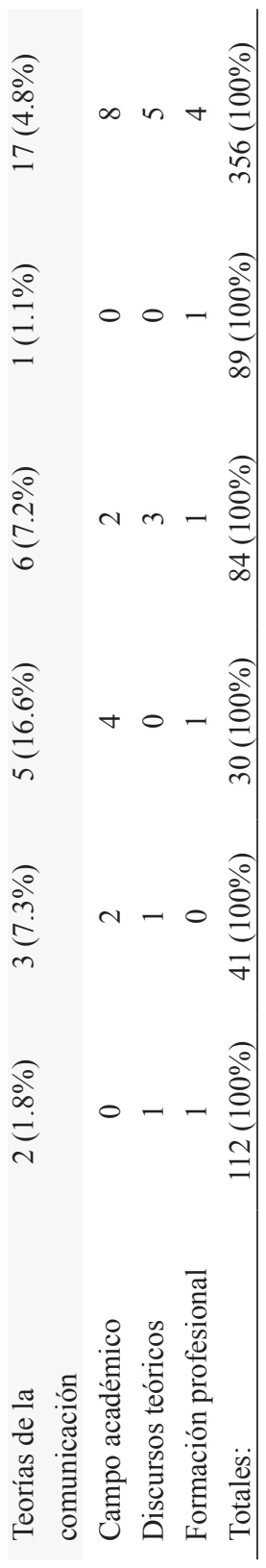


cultivadas por las plantas de profesores que las dirigen e imparten sus cursos. Aunque las seis categorías temáticas están representadas en los cinco programas por al menos una tesis (lo que no sucede en el nivel de las subcategorías, pues más de un tercio de las intersecciones -53/150 - quedan vacías), hay fuertes desbalances entre ellas, tanto en el total como en cada una de las instituciones.

En el conjunto, y en tres de los cinco programas (UNAM, UdeG e ITESO), la categoría con mayor porcentaje de tesis es "Mediaciones e interfaces", la que menos claramente está identificada con los estudios tradicionales de Comunicación, o la que con mayor vehemencia apunta hacia el carácter "posdisciplinario" de la investigación de la Comunicación (Fuentes, 2009; Herbst, 2008). En contrapartida, las categorías más directamente relacionadas con los estudios "de medios" ("Comunicación audiovisual" y "Periodismo" sumadas), sólo están presentes en el ITESM en más de la mitad de las tesis (56.3\%). La "Comunicación organizacional" se encuentra significativamente sólo en la UIA; el estudio de las "Ciberculturas y tecnologías de la comunicación" sobre todo en el ITESM y la UIA, y "Teorías de la comunicación", la categoría menos favorecida, únicamente en el ITESO. Solamente en tres casos hay una concentración de más de $40 \%$ de las tesis de una institución en una categoría: $50 \%$ del ITESO y $41.4 \%$ de la UdeG en "Mediaciones e interfaces", y 42.7\% del ITESM en "Comunicación audiovisual".

Al pasar a las subcategorías queda claro que "Televisión", "Opinión pública", "Educación", "Imaginarios", "Comunicación organizacional" y "Ciberculturas" son temas estudiados en todos los programas, si acaso con alguna excepción ("Comunicación organizacional” y "Opinión pública" en el ITESO; "Imaginarios" en la UIA), aunque en diferentes proporciones. "Producción audiovisual" es "exclusiva" del ITESM, como "Políticas culturales" lo es del ITESO. No obstante, las diferencias detectadas de esta manera no parecen guardar una correlación fuerte con la "orientación" (hacia la "profesionalización" o hacia la "investigación”, según las categorías del PNP), de los programas.

Cada una de las categorías y subcategorías temáticas, como era de esperarse, tiene asociada alguna bibliografía distintiva, aunque en la mayoría de los casos las obras más frecuentemente citadas en las tesis son más generales, las que constituyen la "plataforma central" (Nota 15 del presente artículo; Fuentes, 2008, p.48) y otras. En la Tabla 10 se 


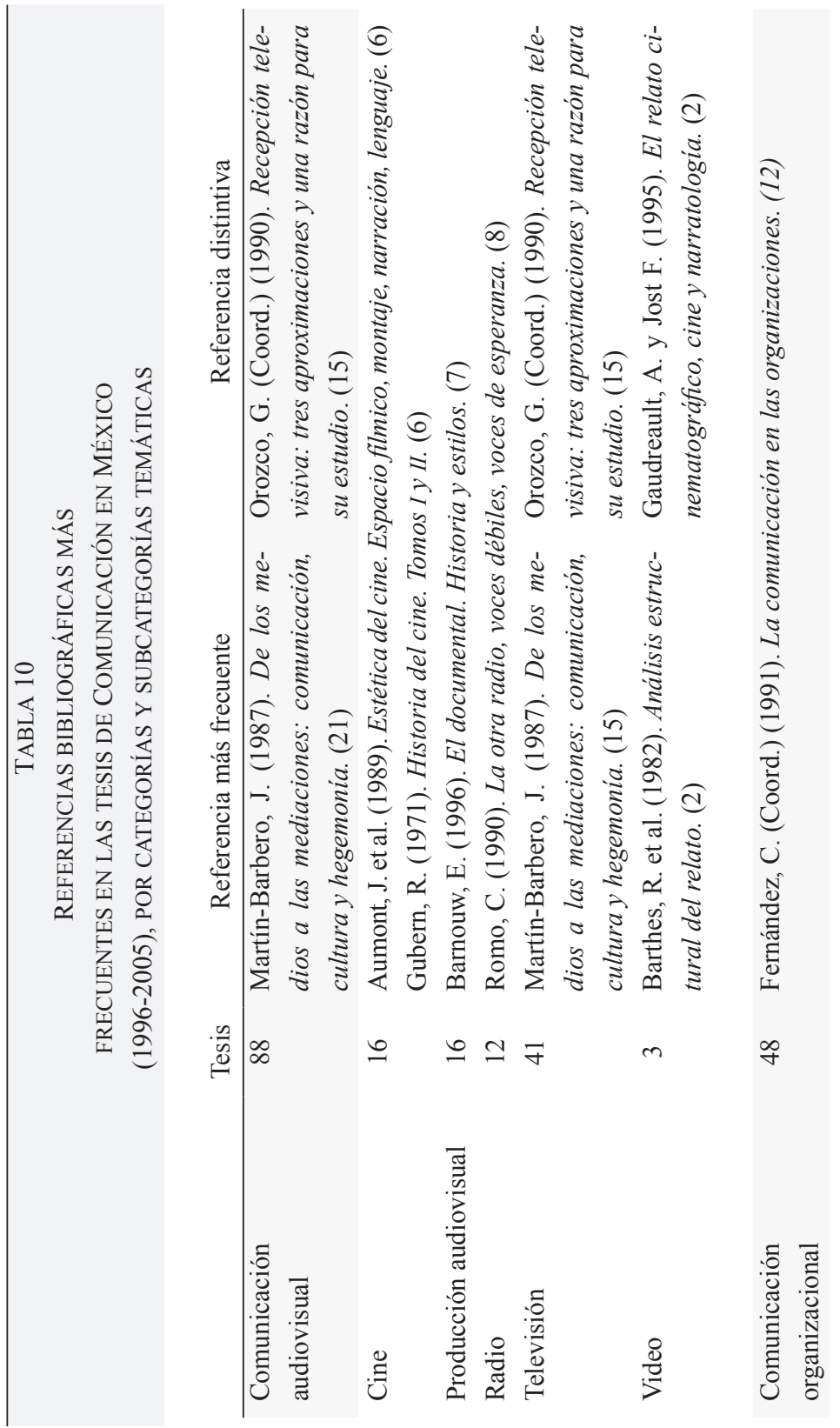




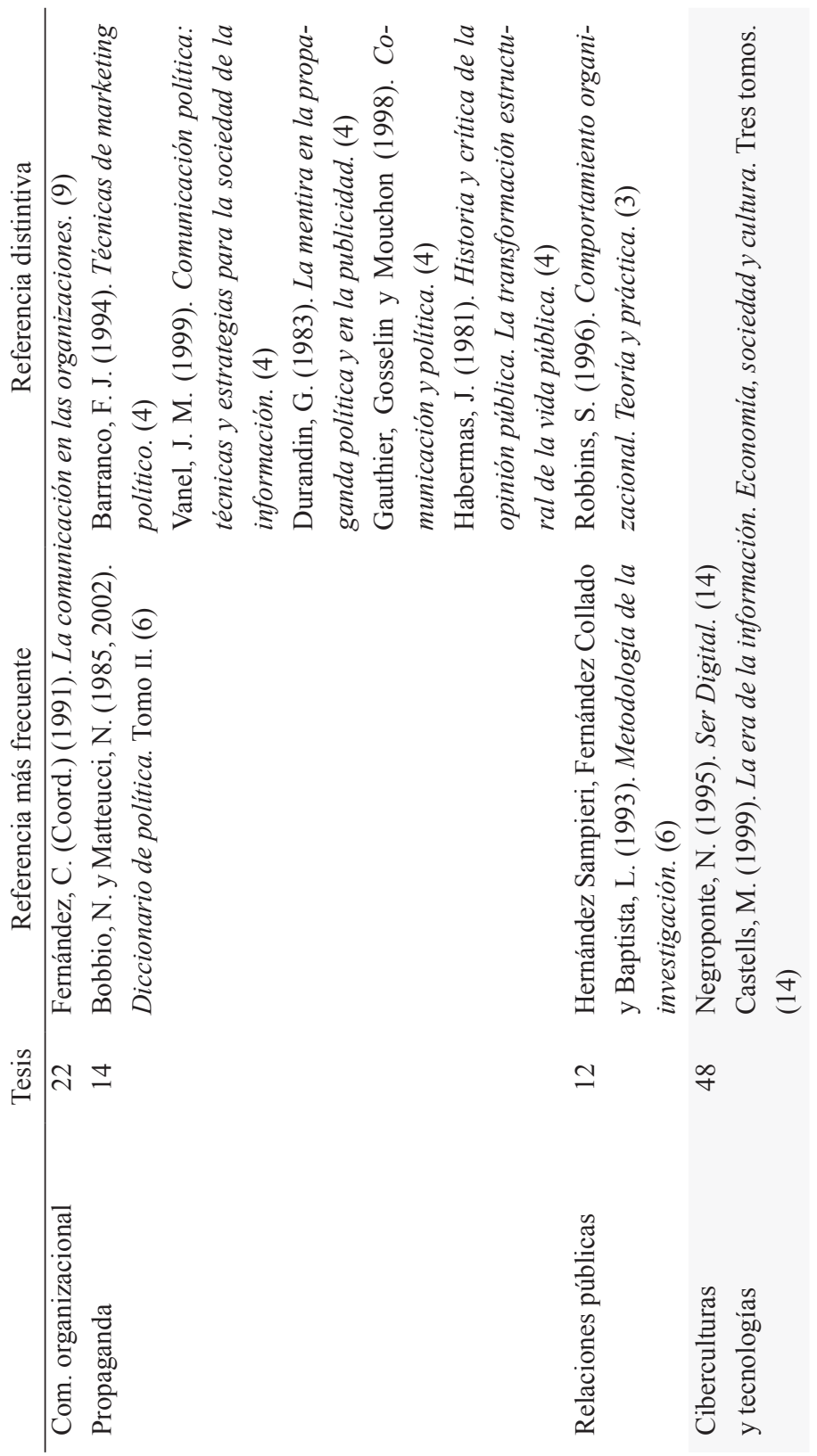



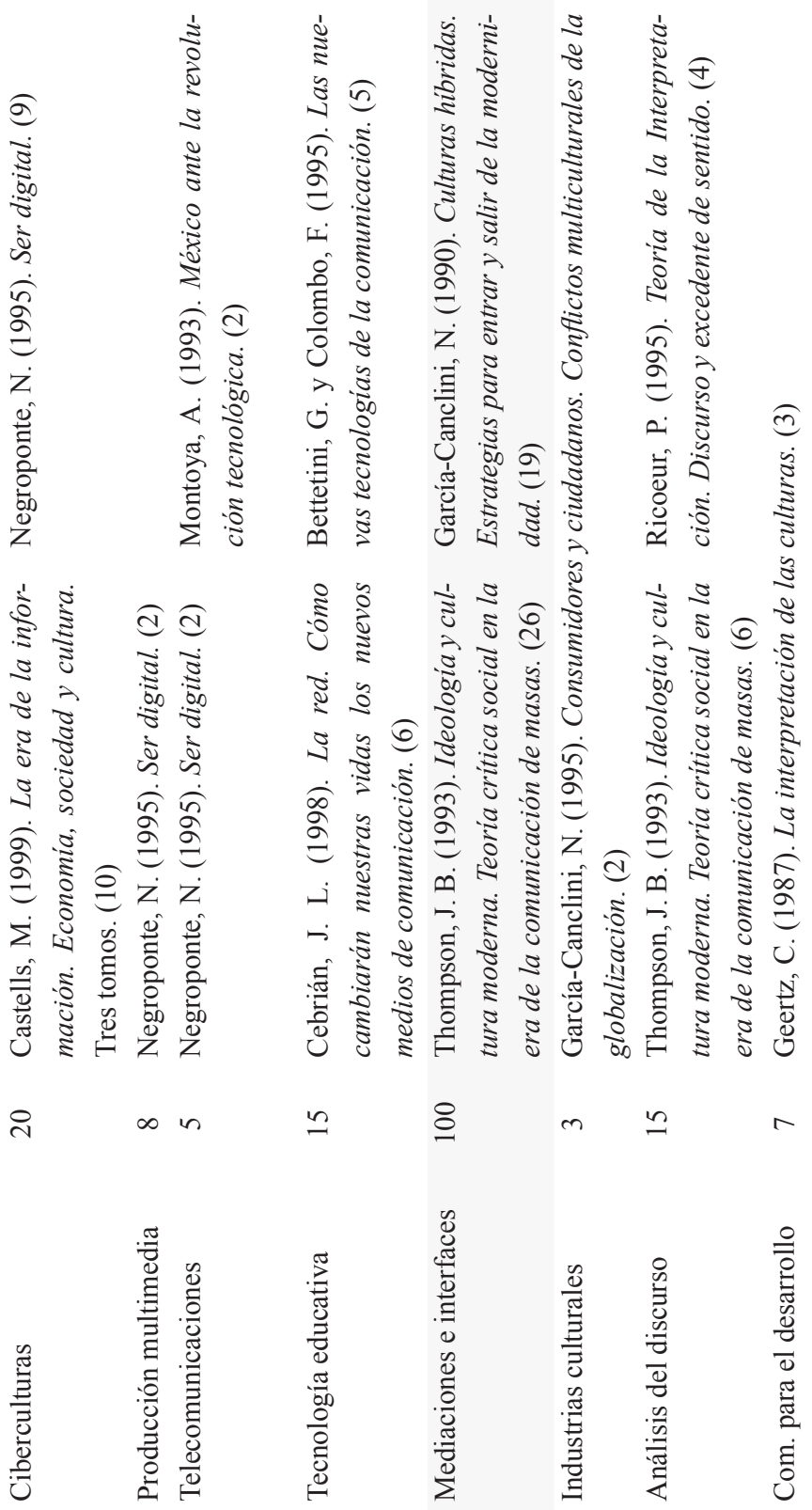


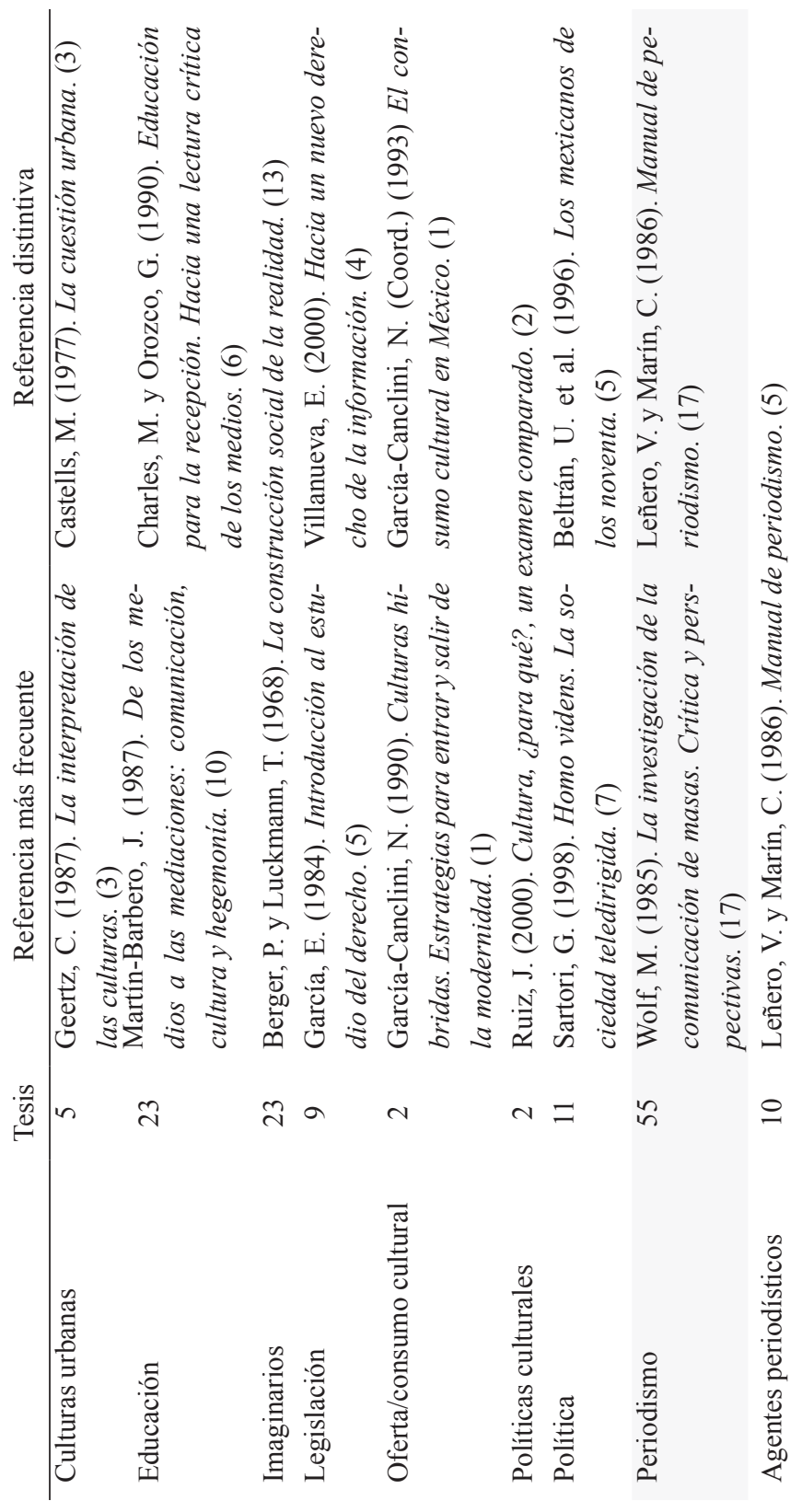



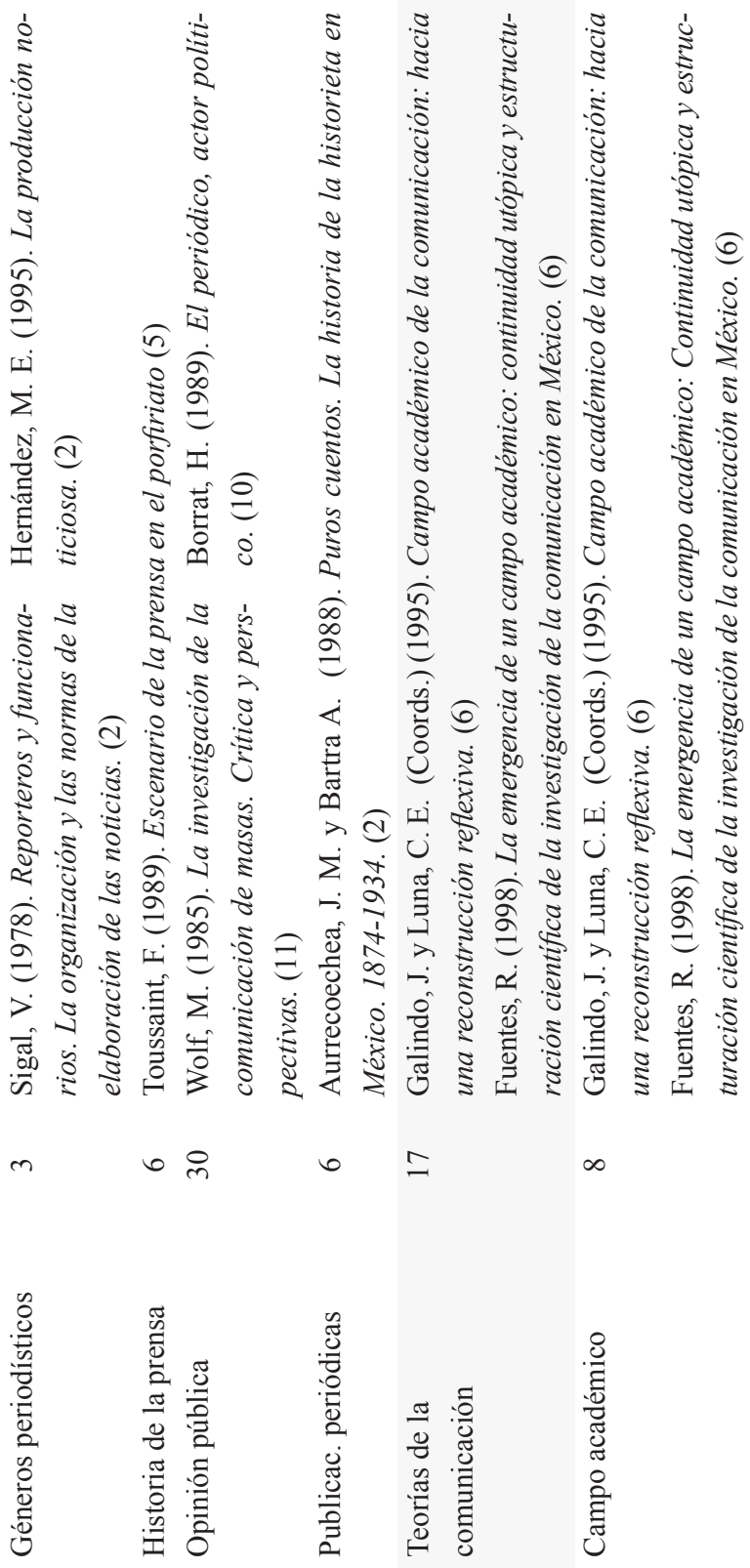


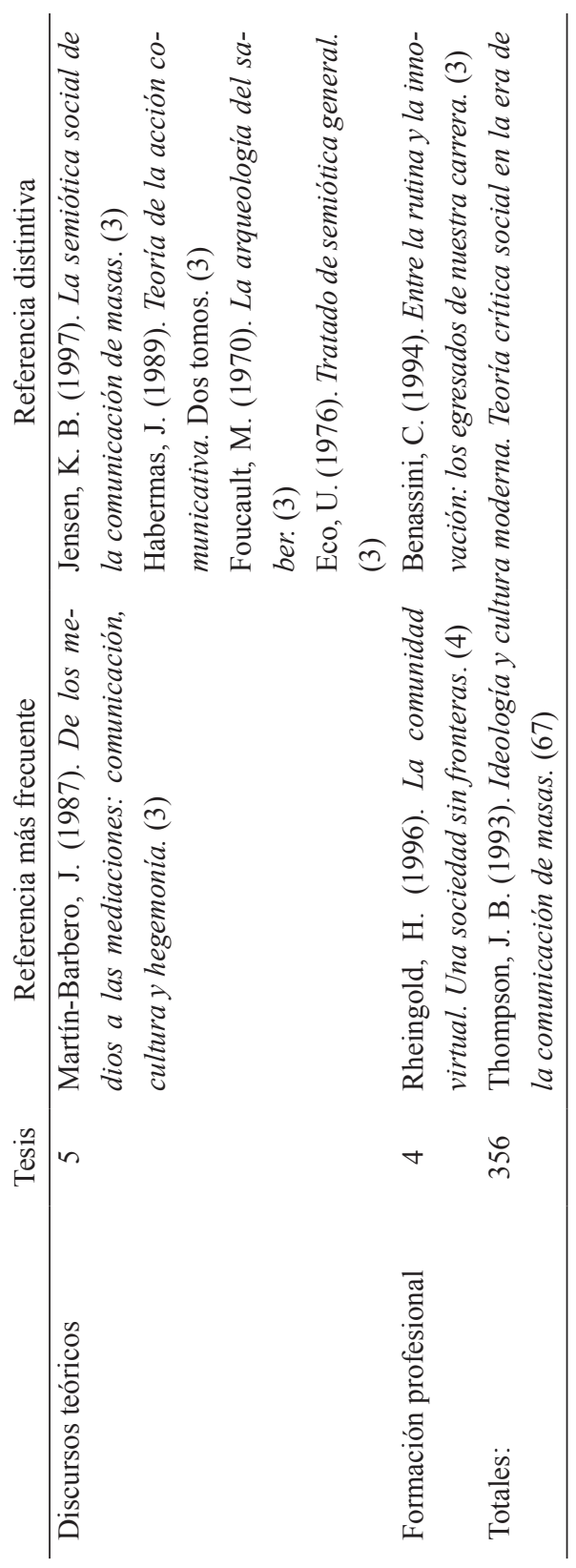


anotan las obras más citadas en las tesis. Nótese, sin embargo, que la proporción de las tesis que las citan es, en la mayor parte de los casos (excepto en las categorías menos "pobladas"), sistemáticamente menor a $50 \%$ de las citas totales a cada obra, lo cual puede interpretarse como otro indicio de fragmentación. ${ }^{21}$

Por otra parte, puede esperarse que los autores mexicanos que participan como profesores y directores de tesis en las maestrías, aparezcan citados con mayor frecuencia en las tesis de sus respectivas instituciones que en las otras (Fuentes, 2008, p.45). Los datos confirman esta tendencia, incluyendo los casos en que los autores han sido profesores en más de una institución durante el periodo estudiado, como puede reconocerse en la Tabla 11.

\section{TABLA 11}

CITAS A 15 INVESTIGADORES MEXICANOS EN TESIS DE MAESTRÍA EN COMUNICACIÓN EN MÉXICO (1996-2005), SEÑALANDO LOS PROGRAMAS DE LOS QUE HAN SIDO PROFESORES Y DIRECTORES DE TESIS

\begin{tabular}{lcccccc}
\multicolumn{1}{c}{$\begin{array}{c}\text { Investigador } \\
\text { mexicano* }\end{array}$} & UNAM & UdeG & ITESO & UIA & ITESM & Total \\
\hline $\begin{array}{l}\text { Guillermo Orozco } \\
\text { Gómez (13) }\end{array}$ & 42 & $51 * *$ & 67 & 73 & 51 & 284 \\
$\begin{array}{l}\text { Raúl Fuentes Navarro } \\
(15)\end{array}$ & 3 & 36 & 67 & 50 & 3 & 159 \\
$\begin{array}{l}\text { Enrique E. Sánchez } \\
\text { Ruiz (3) }\end{array}$ & 14 & 56 & 28 & 20 & 27 & 145 \\
$\begin{array}{l}\text { José Carlos Lozano } \\
\text { Rendón (26) }\end{array}$ & 6 & 13 & 5 & 11 & 67 & 102 \\
Raúl Trejo Delarbre & 38 & 16 & 1 & 14 & 15 & 84 \\
$\begin{array}{l}\text { Rossana Reguillo Cruz } \\
\text { (2) }\end{array}$ & 3 & 34 & 29 & 7 & 3 & 76
\end{tabular}

21 La obra más citada en todo el corpus, Ideología y cultura Moderna. Teoría Crítica Social en la era de la comunicación de masas, de John B. Thompson, está referida en apenas $18.8 \%$ de las tesis. 


\begin{tabular}{lcccccc}
\multicolumn{1}{c}{$\begin{array}{c}\text { Investigador } \\
\text { mexicano* }\end{array}$} & UNAM & UdeG & ITESO & UIA & ITESM & Total \\
\hline $\begin{array}{l}\text { Gilberto Giménez } \\
\text { Montiel }\end{array}$ & 25 & 15 & 10 & 17 & 5 & 72 \\
Javier Esteinou Madrid & 19 & 5 & 7 & 17 & 12 & 60 \\
$\begin{array}{l}6) \\
\text { Delia Ma. Crovi }\end{array}$ & 22 & 5 & 1 & 4 & 8 & 40 \\
$\begin{array}{l}\text { Drueta (12) } \\
\text { Cecilia Cervantes }\end{array}$ & 5 & 28 & 0 & 3 & 2 & 38 \\
$\begin{array}{l}\text { Barba (3) } \\
\text { Francisco de J. Aceves }\end{array}$ & 7 & 20 & 0 & 2 & 4 & 33 \\
$\begin{array}{l}\text { González (3) } \\
\text { Fátima Fernández }\end{array}$ & 14 & 3 & 2 & 3 & 1 & 23 \\
$\begin{array}{l}\text { Christlieb } \\
\text { Susana González }\end{array}$ & 19 & 1 & 0 & 1 & 0 & 21 \\
$\begin{array}{l}\text { Reyna (6) } \\
\text { Florence Toussaint }\end{array}$ & 16 & 3 & 0 & 1 & 0 & 20 \\
$\begin{array}{l}\text { Alcaraz (5) } \\
\text { María Elena }\end{array}$ & 1 & 18 & 0 & 0 & 0 & 19 \\
Hernández Ramírez (6) & & & & & & \\
\hline
\end{tabular}

* Entre paréntesis, número de tesis dirigidas, incluidas en el corpus.

** Las casillas sombreadas señalan los programas donde los investigadores han sido, durante el periodo, profesores y directores de tesis.

En síntesis, los datos analizados, más allá de algunas esperables diferencias entre las cinco instituciones en cuanto a la producción académica que se manifiesta en las tesis de maestría, permiten reconocer algunos rasgos comunes de reproducción, más que de los agentes especializados para las profesiones o la academia,22 de las características más distintivas del campo académico. Puede confirmarse que:

el desarrollo de la investigación de la comunicación en México, según su proyección de tendencias en las tesis de maestría, no tiende hacia una

22 Para el análisis de la cual serían pertinentes otros datos no presentes en las bibliografías de las tesis, material básico del presente proyecto. 
convergencia conceptual o a una consolidación disciplinaria, sino hacia lo contrario: a una creciente diversificación de marcos de fundamentación y a una especialización temática que se basa en marcos transdisciplinarios de las ciencias sociales y las humanidades (Fuentes, 2008, p.51).

El "estancamiento concentrado" que se ha formulado para describir el estado actual de desarrollo del campo académico de la comunicación en México (Fuentes, 2009), al referirse sobre todo al escaso crecimiento estructural (cuantitativo y cualitativo) de su producción científica-académica, en sus propios términos y en contraste directo con los posgrados y la investigación de la comunicación en Brasil,23 es relativamente fácil de documentar en el plano institucional, pero quedan abiertas muchas cuestiones en términos de la dimensión propiamente "intelectual" del campo, algunas de las cuales se pueden relacionar con el análisis realizado.

\section{ALGUNAS HIPÓTESIS SOBRE CONVERGENCIAS Y DIVERGENCIAS EN EL CAMPO ACADÉMICO DE LA COMUNICACIÓN}

A mediados de 2008, cuando en los debates académicos internacionales parecía prevalecer la fragmentación como clave de interpretación del desarrollo del campo de estudios de la comunicación, y muy probablemente como consecuencia de ello, apareció la Enciclopedia Internacional de la Comunicación, publicada en 12 tomos, con el profesor alemán Wolfgang Donsbach (2008) como editor principal. El proyecto subyacente pretendía organizar los componentes de la fragmentación y hacerlo, además, desde una perspectiva "internacional".

Con la colaboración de más de mil académicos de aproximadamente 70 países, la ambición de la obra genera, al menos, la abrumadora sen-

23 Por tratarse de un proyecto comparativo con ese país, pero también podría analizarse el caso español, dado que a fines de los años ochenta la estructura de la producción académica en el campo de la comunicación era aproximadamente equivalente en los tres países (Fuentes, 1998, pp.31-38) y el crecimiento en España y en Brasil en los últimos 20 años es muchísimo mayor que en México. 
sación de un campo de estudios absolutamente inabarcable, donde la producción de conocimiento y las articulaciones intra y extra académicas que manifiesta en buena parte del mundo, desbordan cualquier intento de reconocimiento sistemático. Ante esta condición, la Enciclopedia propone una estructura de 29 "áreas editoriales", muchas de las cuales podrían corresponder a "subcampos" de estudio de la comunicación, ${ }^{24}$ hipotéticamente referidos al cultivo "internacional" del campo, sobre el que Robert Craig (2008) señala tres características comunes: en primer lugar, el crecimiento, "estimulado en muchos lugares por la necesidad de personal capacitado para los medios, condición que acarrea muchos problemas para el desarrollo propiamente académico del campo". En segundo lugar, la dependencia extrema "con respecto a conceptos y prácticas de origen estadounidense y europeo, coincidente con una fuerte necesidad de conocimiento cultural y localmente relevante, lo que contribuye a una creciente internacionalización, en condiciones de gran diversidad". Y, finalmente, un aparente "consenso internacional de que el nombre y el concepto subyacente hacia los que todos contribuyen ... es Comunicación" (p. 678).

Esta triple caracterización podría matizarse desde la perspectiva particular de algunos países, como México, donde el "crecimiento" se encuentra sólo (y en grado extremo, de "hipertrofia") en el nivel

24 Y que también, eventualmente, podrían emplearse como categorías de clasificación temática. Las 29 "áreas editoriales” de la Enciclopedia son: Comunicación como campo y disciplina; Legislación y políticas de comunicación y medios; Comunicación y cambio social/conductual; Comunicación y tecnología; Teoría y filosofía de la comunicación; Comunicación para el desarrollo; Comunicación y desarrollo humano; Exposición a contenidos comunicacionales; Estudios feministas y de género; Procesamiento de la información y cognición; Comunicación educativa/instruccional; Comunicación intercultural e intergrupal; Comunicación internacional; Comunicación interpersonal; Periodismo; Lenguaje e interacción social; Economía de los medios; Efectos de los medios; Historia de los medios; Producción y contenido de los medios; Sistemas de medios en el mundo; Comunicación organizacional; Comunicación política; Comunicación popular; Percepción de la realidad a través de los medios; Métodos de investigación; Estudios retóricos; Comunicación estratégica, relaciones públicas y publicidad; Comunicación visual. 
de los programas de licenciatura;25 la tensión entre la dependencia y el desarrollo nacional en investigación de la comunicación se ha equilibrado mejor que en otros países, y el nombre "(Ciencias de la) Comunicación" sigue siendo un identificador común, pero no siempre reconocido como tal.

En su apretada y bien documentada síntesis sobre la "Comunicación como campo y disciplina", Craig reconstruye las tendencias y los debates principales que condicionan el reconocimiento y la organización de los estudios sobre la comunicación en todo el mundo y subraya los inexorables componentes de aplicación social que los caracteriza, así como la creciente demanda de intervenciones expertas en las sociedades contemporáneas. Y en términos de un "prospecto de futuro", reconociendo que los debates no han generado acuerdos sobre si la investigación de la comunicación debería tender a establecerse como una disciplina en el mismo sentido que lo son la lingüística, la sociología o la economía, o si ya lo ha hecho (al menos en Estados Unidos), plantea una fórmula que puede servir bien, al menos, para interpretar las principales tendencias que van siendo documentadas:

La cuestión no es si el de la comunicación seguirá siendo un campo interdisciplinario, pues ciertamente lo seguirá siendo. La pregunta abierta es si la comunicación puede también tener un núcleo teórico que permita a los investigadores de la comunicación abordar tópicos interdisciplinarios desde un punto de vista disciplinario particular, que aporte valor real a la empresa interdisciplinaria. La creciente centralidad de la comunicación como tema de la cultura global, involucra a la disciplina de la comunicación en una "doble hermenéutica", un proceso en el que el campo académico deriva mucho de su identidad y de su coherencia del profundo y comprometido involucramiento con la comunicación como una categoría de la práctica social, al mismo tiempo que contribuye a la dinámica evolución de esa misma categoría

25 Según el informe final de un proyecto de la Federación Latinoamericana de Facultades de Comunicación Social (FELAFACS) y la UNESCO, recientemente publicado, en México hay más de mil programas de este nivel, con graves problemas de todo tipo (FELAFACS-UNESCO, 2009). 
cultural, que constituye el objeto central y definitorio de estudio de la disciplina (p. 686). 26

Esta consideración se relaciona directamente con los interminables debates sobre la "interdisciplinariedad", ante los que Susan Herbst (2008) opone la idea de la "posdisciplinariedad", una forma de organización académica adecuada para abordar problemas que rebasan los marcos disciplinarios tradicionales (como los campos de estudios relacionados con las identidades socioculturales) y que, como alternativa a la "antidisciplinariedad", supone "un creciente eclecticismo metodológico y temático en la investigación y la enseñanza" (Menand, 2001). Herbst apunta a la presencia de un tal eclecticismo en buena parte de los orígenes y el desarrollo de los estudios de la comunicación, a los que ella misma y diversos diagnósticos recientes realizados desde otras latitudes, caracterizan como carentes tanto de consistencia epistemológica como de relevancia social (Donsbach, 2006; Herkman, 2008; Jensen, 2002; Martín-Barbero, 2002, 2009; Scolari, 2008).

A partir de esta clave de interpretación se pueden encontrar algunos ejemplos de buena calidad entre las tesis de maestría en Comunicación analizadas que pudieran reconocerse como investigaciones "posdisciplinarias" de la Comunicación, sobre todo en la categoría "Mediaciones e interfaces" (la que mayor número de tesis agrupa en el corpus analizado y que es cultivada en las cinco maestrías), tanto como tesis de buena

26 "The question is not whether communication will continue to be an interdisciplinary field, as it certainly will do. The open question is whether communication may also have a theoretical core that enables communication scholars to approach interdisciplinary topics from a distinct disciplinary viewpoint that adds real value to the interdisciplinary enterprise. The growing centrality of communication as a theme in global culture involves the discipline of communication in a "double hermeneutic", a process in which the academic field derives much of its identity and coherence from its profound engagement with communication as a category of social practice while also contributing to the ongoing evolution of that very cultural category that constitutes the discipline's centrally defining object of study." 
calidad que se encuadran en las categorías más "tradicionales", como las de "Periodismo" o "Comunicación organizacional". No hay más datos disponibles para conjeturar sobre lo que comparten unas y otras tesis entre sí y con los programas donde se generaron, más que la diversidad de fuentes bibliográficas a las que recurrieron, donde sin embargo se conserva la referencia a textos como los caracterizados como la "plataforma central" (cita 15 del presente artículo), que probablemente aportan los elementos de esas intersecciones entre ciencias sociales y humanidades en las que se sustenta un hipotético pero muy concreto "eclecticismo metodológico" posdisciplinario.

Si se considera que la investigación de la comunicación se ha fragmentado en las últimas décadas debido a una sobrevaloración de sus componentes axiológicos, buscando la aportación de mejores comprensiones o de soluciones a problemas socioculturales relevantes en el entorno, sobre la consistencia teórico-metodológica y epistemológica que caracterizaría a una "disciplina", la hipótesis de la posdisciplinariedad podría generar algunas claves interesantes de interpretación del desarrollo académico del campo, si bien también habría que considerar los "riesgos" asociados, en especial la falta de rigor y consistencia en el tratamiento de temas que, al provenir sobre todo de la "práctica social" o de la "cultura global" que señala Craig, orientaran la investigación más en función de la inmediatez y la superficialidad que caracterizan a la comunicación mediada, que a la profundidad crítica de los análisis académicos.

Al mismo tiempo quedaría por evaluarse la articulación de los productos de investigación académica analizados, las tesis de maestría, con los propósitos de profesionalización universitaria de los programas en los que se realizan, aunque es evidente que en México -y no necesariamente en otros países-, los posgrados acreditados tienen una incidencia mínima en los escenarios socioculturales donde su ubican los fenómenos "de comunicación” que construyen, en su mayor parte, como objetos de estudio.

\section{Bibliografía}

ANUIES-Anuario Estadístico (2007). Citado por Rosaura Ruiz Gutiérrez (s.f.). Tendencias y perspectivas de la educación superior, la 
ciencia, la tecnología y la innovación en México. Documento publicado en el sitio institucional de la Academia Mexicana de Ciencias. Recuperado el 3 de octubre de 2009 de http://www.amc.unam.mx/ Craig, R. T. (1999). Communication theory as a field. Communication Theory, 9, 119-161.

Craig, R. T. (2008). Communication as a field and discipline. En W. Donsbach (Ed.), The International Encyclopedia of Communication. Tomo II. pp. 675-688. Nueva York: Blackwell.

Donsbach, W. (2006). The identity of communication research. Journal of Communication. 56, 3: 437-448.

Donsbach, W. (Ed.). (2008). The International Encyclopedia of Communication. Doce tomos. Nueva York: Blackwell.

FELAFACS-UNESCO (2009). Mapa de los centros y programas de formación de comunicadores y periodistas en América Latina y el Caribe. Informe Final. Lima: FELAFACS-UNESCO /Banco Santander.

Fuentes, R. (1988). La investigación de comunicación en México. Sistematización documental 1956-1986. México: Edicom.

Fuentes, R. (1996). La investigación de la comunicación en México. Sistematización documental 1986-1994. Guadalajara: Universidad de Guadalajara/ ITESO.

Fuentes, R. (1998). La emergencia de un campo académico: continuidad utópica y estructuración científica de la investigación de la comunicación en México. Guadalajara: ITESO/ UdeG.

Fuentes, R. (2003). La investigación académica sobre comunicación en México. Sistematización documental 1995-2001. Guadalajara: ITESO.

Fuentes, R. (2004). La constitución científica del campo académico de la comunicación en México y en Brasil: análisis comparativo. Protocolo de investigación presentado al Comité de Ciencias Sociales del Fondo de Ciencia Básica del Consejo Nacional de Ciencia y Tecnología.

Fuentes, R. (2006). La constitución científica del campo académico de la comunicación. Un análisis comparativo México-Brasil. Revista Latinoamericana de Ciencias de la Comunicación, 5, 48-55.

Fuentes, R. (2007a). Las marcas de la profesionalización avanzada: un acercamiento descriptivo a las tesis de maestría en comunicación 
del ITESO y de la UdeG, a través de sus referentes bibliográficos. Comunicación y Sociedad, 7, 11-44. Nueva época.

Fuentes, R. (2007b). Fontes bibliográficas da pesquisa acadêmica nos cursos de pós-graduação em comunicação no Brasil e no México: uma aproximação da análise comparativa. MATRIZes, 1, 165-177.

Fuentes, R. (2008). Bibliografías, biblionomías, bibliometrías: los libros fundamentales en el estudio de la comunicación. Comunicación y Sociedad, 10, 15-53. Nueva época.

Fuentes, R. (2009). Comunicación, cultura y sociedad: hacia un modelo de práctica post-disciplinaria de investigación social. Ponencia en el II Congreso Nacional de Ciencias Sociales, Consejo Mexicano de Ciencias Sociales, Oaxaca.

Herbst, S. (2008). Disciplines, intersections, and the future of communication research. Journal of Communication, 58, 4, 603-614.

Herkman, J. (2008). Current trends in media research. Nordicom Review, 29, 1: 145-159.

Jensen, K. B. (2002). The social origins and uses of media and communication research. En Jensen (Ed.), A handbook of media and communication research. Qualitative and Quantitative Methodologies. Londres, Nueva York: Routledge.

Martín-Barbero, J. (2002). Oficio de cartógrafo. Travesías latinoamericanas de la comunicación en la cultura. Santiago de Chile: FCE.

Martín-Barbero, J. (Coord.). (2009). Entre saberes desechables y saberes indispensables (agendas de país desde la comunicación). Bogotá: Centro de Competencia en Comunicación para América Latina, Friedrich Ebert Stiftung.

Menand, L. (2001). The marketplace of ideas. American Council of Learned Societies. Occasional Paper, 49.

Romancini, R. (2006). O campo científico da Comunicação no Brasil: institucionalização e capital científico. Tese apresentada ao Programa de Pósgraduação em Ciências da Comunicação da Escola de Comunicações e Artes da Universidade de São Paulo, como requisito parcial para a obtenção do título de doutor em Ciências da Comunicação, na Área de Concentração Teoria e Pesquisa em Comunicação. 
PNPC-Padrón Nacional de Posgrados de Calidad. Recuperado el 3 de octubre de 2009 de http://www.conacyt.gob.mx/Calidad/Listado_ PNPC_2009.pdf

Scolari, C. (2008). Hipermediaciones. Elementos para una teoría de la comunicación digital interactiva. Barcelona: Gedisa (Cibercultura). 